\title{
Willingness-to-pay for improvement of hypothetical health status in patients visiting the emergency department: A contingent valuation study
}

\author{
Hesam Seyedin $^{\mathrm{a}}$, Mehdi Safari ${ }^{\mathrm{b}, \mathrm{c}, *}$, Elaheh Parnian ${ }^{\mathrm{d}}$ \\ ${ }^{a}$ Department of Health in Disasters and Emergencies, School of Health Management and Information Sciences, Iran University of Medical Sciences, No 6, Rashid Yasemi St., \\ Vali-e-asr Ave., 1995614111, Tehran, Iran \\ ${ }^{\mathrm{b}}$ Health in Disasters and Emergencies, School of Health Management and Information Sciences, International Campus (IUMS-IC), Iran University of Medical Sciences, No \\ 6, Rashid Yasemi St., Vali-e-asr Ave., 1995614111, Tehran, Iran \\ ${ }^{\mathrm{c}}$ Department of Health in Disasters and Emergencies, School of Public Health and Safety, Shahid Beheshti University of Medical Sciences, Tehran, Iran \\ ${ }^{\mathrm{d}}$ School of Health Management and Information Sciences, Iran University of Medical Sciences, Tehran, Iran
}

\section{A R T I C L E I N F O}

\section{Keywords:}

Emergencies

Cost benefit analysis

Health

\begin{abstract}
A B S T R A C T
Background: The use of willingness-to-pay (WTP) to value the benefits of health (care) in monetary terms is increasing. The objective of this study was to estimate private and altruistic willingness to pay for improvement of hypothetical health status in patients visiting the emergency department.

Methods: A cross-sectional study was used from June to July 2018. We surveyed 300 patients visiting a hospital emergency department in Tehran, Iran. Data were collected via open-ended questionnaire in a face to face interview. We asked them about the maximum amount of money they were willing to pay for improvement of hypothetical health status using contingent valuation method. Determinant factors on willingness to pay was calculated through a regression model. Data were analyzed on STATA version 13.

Results: The mean of willingness to pay increases with worsening health status. The average of private willingness to pay for improvement from first and last health status were \$ 101 and \$ 714 respectively. The average of altruistic willingness to pay for improvement from first and last health status were \$ 74 and \$ 231 respectively. The mean of willingness to pay was influenced by household monthly income $(\mathrm{P}<0.01)$. Age, sex, marital status and education don't have significant associations with willingness to pay.

Conclusions: Our study findings show that all people are willing to pay for improvement from health status and The WTP amount is higher for those who have higher incomes. This information may be useful for health policy maker in the decision-making process.
\end{abstract}

\section{Introduction}

There is an increasing interest in cost-benefit analysis in the economic evaluation of health care services, cost-benefit analysis measures the benefits of health care in monetary terms. ${ }^{1}$ There are two main methods to allocate monetary values to life and health. The first method is human-capital and friction cost measures. ${ }^{2,3}$ As a second method, willingness to pay for health care services is studied based on individuals' preferences ${ }^{4}$. The use of willingness to pay is increasing to value the benefits of health (care) in monetary terms. ${ }^{5-7}$ Willingness to pay is the maximum amount of income an individual is willing to give up to ensure that a proposed service or good is available. ${ }^{8}$ One technique for estimating WTP is contingent valuation method, which developed in the structure of cost-benefit analysis, which are necessary to attribute value to goods or services that cannot be traded in a market. ${ }^{9}$ It is a valid method for estimating the value placed by people on health care interventions. ${ }^{9}$ One application of $\mathrm{CV}$ method is for measuring altruistic activities in health sector. For example, Liu et al. used CV to estimate Taiwanese mothers WTP to protect themselves and their children from suffering a minor illness-a cold. They found that mothers' altruistic WTP to protect their children from a cold is higher than their private WTP to protect themselves from a cold of equivalent duration and severity. ${ }^{10}$ Andersson (2009) indicated that altruistic willingness to pay was about one-third the private willingness to pay. ${ }^{11}$ The purpose of this study was to estimate willingness to pay for improvement of hypothetical health status in patients visiting the emergency department.

\footnotetext{
${ }^{*}$ Corresponding author. Health in Disasters and Emergencies, School of Health Management and Information Sciences, International Campus (IUMS-IC), Iran University of Medical Sciences, No 6, Rashid Yasemi St., Vali-e-asr Ave., 1995614111, Tehran, Iran.

E-mail addresses: h.seyedin@gmail.com (H. Seyedin), safari.pe@gmail.com (M. Safari), e.parnian2012@gmail.com (E. Parnian).
} 


\section{Methods}

A cross-sectional study was used from June to July 2018. We surveyed 300 patients visiting a hospital emergency department in Tehran, Iran. The sample size was determined using the following equation in which $\mathrm{p}=0.8, \mathrm{~d}=0.045$.

$N=\frac{Z_{1-\frac{\alpha}{2}} p(1-p)}{d^{2}}=300$

The 300 sample were randomly selected from patients that reffered to a hospital emergency department in Tehran, Iran. Data were collected via open-ended questionnaire in a face to face interview.

\section{Measurement issues}

Four methods used to measure willingness to pay in economic evaluation: open-ended, discrete choice, payment card and bidding games. Open-ended method asks the respondent the amount of money he/she is willing to pay for a specified good or service. Take-it-or-leaveit question proposes a bid for the good and asks if the respondent is willing to pay that price. Payment card technique lists a range of prices and the respondent is asked to mark the maximum amount of money he/she is willing to pay. Bidding games offer a sequence of values for the respondent who answers either yes or no to the proposed bid. The sequence of values finally converges to the estimate about individual's willingness to pay. These different techniques have been assessed widely in the literature. ${ }^{1,} 12-14$ We selected the open-ended method for this study, because the open-ended question method is a good method for finding first estimates and there is little information about willingness to pay in health care. Also, the open-ended method is easier to apply than other methods. In the open-ended questionnaire, it was possible to compare private WTP and altruistic WTP.

\section{Private and altruistic WTP for hypothetical health improvement}

Hypothetical health states with different severity levels was considered to estimate the willingness to pay. Six levels regarding mobility were used from a scale constructed by Nord. ${ }^{15}$

1. Can move about without difficulty anywhere, but has difficulties with walking more than a kilometer.

2. Can move about with difficulty at home, but has difficulties in stairs and outdoors.

3. Moves about with difficulty at home. Needs assistance in stairs and outdoors.

4. Can sit. Needs assistance to move about - both at home and outdoors.

5. To some degree bedridden. Can sit in a chair part of the day if helped up by others.

6. Completely bedridden

\section{Private WTP question}

For private WTP, the respondents were to disclose their willingness to pay to be treated from each health state and was presented in the following way: "If you are suffering from the different health states that stated in previous part. How much are you willing to pay to be treated from each health state?"

\section{Altruistic WTP question}

The scenario was the same as in the Private WTP question, but instead of disclosing their willingness to pay for their own health improvement, this question dealt with the respondent's willingness to pay

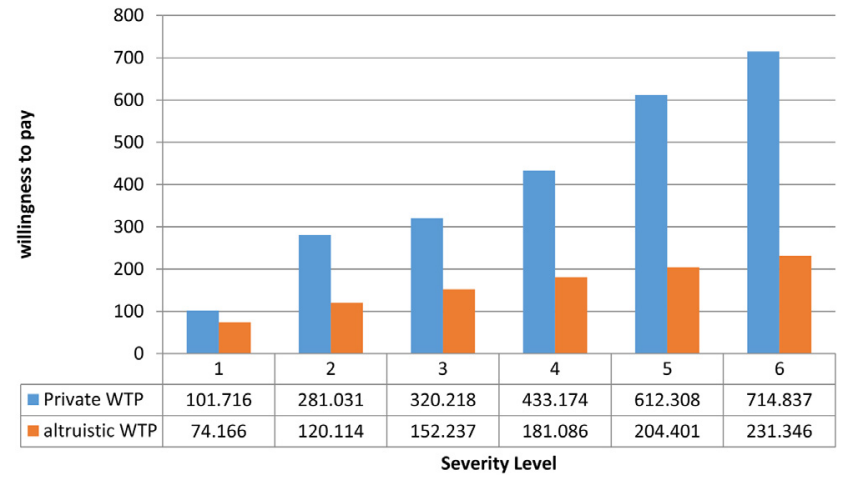

Fig. 1. The mean of willingness to pay for improvement of hypothetical health status.

Table 1

Socio demographic characteristic of participant.

\begin{tabular}{llll}
\hline Variables & & Frequency & Percentage \\
\hline \multirow{2}{*}{ Age } & $<40$ & 109 & 36 \\
& $\geq 40$ & 191 & 64 \\
Sex & Male & 177 & 59 \\
\multirow{3}{*}{ Marital Status } & Female & 123 & 41 \\
& Single & 129 & 43 \\
Education & Married & 171 & 57 \\
\multirow{3}{*}{ Supervisor } & non-academics & 114 & 38 \\
& academics & 186 & 62 \\
Insurance & Own & 212 & 71 \\
& Others & 88 & 29 \\
& Armed force & 12 & 4 \\
& Health service & 63 & 21 \\
& Social security & 208 & 69 \\
\hline
\end{tabular}

for someone else's possibility to be treated from each health state. This question was presented in the following way: "Assume now, that a stranger is suffering from the described different health states. How much are you willing to pay for stranger's treatment of any health status?"

\section{Data analysis}

Data were analyzed on STATA version 13 . To compare private WTP and altruistic WTP was applied mean of willingness to pay in every health states. Determinant factors on willingness to pay was calculated through a regression model.

Ln $\mathrm{WTP}_{\mathrm{HSn}}=\beta_{0}+\beta_{1}$ Age $+\beta_{2}$ Sex $+\beta_{3}$ Marital status $+\beta_{4}$ Income + $\beta_{5}$ Education

$\mathrm{n}=1,2,3,4,5$ and 6

$\mathrm{WTP}_{\mathrm{HSn}}$ means the average of willingness to pay for improvement from health status 1 to 6 .

\section{Results}

Scio-demographic characteristics of the study population: a total of 300 people participated in this study. All of respondent have insurance and more than $60 \%$ have academics education. Furthermore, about $59 \%$ of participant was male (Table 1 ).

Fig. 1 shows the mean value of private and altruistic WTP. The private WTP was 101, 281.320, 433, 612 and 714 US \$ for health status 1 to 6 . The altruistic WTP was 74, 120, 152, 181, 204 and 231 US \$ for health status 1 to 6 .

Determinant factors on private willingness to pay was shown in Table 2. The results showed that the mean of willingness to pay was 
Table 2

Determinant factors on private willingness to pay for improvement of hypothetical health status.

\begin{tabular}{|c|c|c|c|c|c|c|}
\hline \multirow[t]{2}{*}{ Explanatory Variables } & Model 1 & Model 2 & Model 3 & Model 4 & Model 5 & Model 6 \\
\hline & $\log \mathrm{WTP}_{\mathrm{HS} 1}$ & $\log \mathrm{WTP}_{\mathrm{HS} 2}$ & $\log \mathrm{WTP}_{\mathrm{HS} 3}$ & Log $\mathrm{WTP}_{\mathrm{HS} 4}$ & Log $\mathrm{WTP}_{\mathrm{HS5}}$ & Log WTP $\mathrm{WSG}_{\mathrm{H}}$ \\
\hline Constant & $-7.84^{\mathrm{a}}$ & $-4.93^{\mathrm{a}}$ & $-3.21^{\mathrm{a}}$ & $-2.34^{\mathrm{a}}$ & $-1.58^{\mathrm{a}}$ & -0.83 \\
\hline Age & $0.26(0.07)$ & $0.25(0.09)$ & $0.14(0.07)$ & $0.11(0.09)$ & $0.19(0.04)$ & $0.07(0.05)$ \\
\hline Sex & $0.02(0.05)$ & $0.07(0.09)$ & $0.06(0.07)$ & $0.005(0.04)$ & $0.01(0.04)$ & $0.07(0.06)$ \\
\hline Marital status & $0.1(0.05)$ & $0.02(0.04)$ & $0.03(0.05)$ & $0.09(0.03)$ & $0.003(0.02)$ & $0.05(0.04)$ \\
\hline Income & $1.37^{\mathrm{a}}(0.05)$ & $1.26^{\mathrm{a}}(0.05)$ & $1.21^{\mathrm{a}}(0.04)$ & $1.05^{\mathrm{a}}(0.03)$ & $1.03^{\mathrm{a}}(0.02)$ & $1.01^{\mathrm{a}}(0.02)$ \\
\hline Education & $0.14(0.08)$ & $0.21(0.09)$ & $0.07(0.05)$ & $0.04(0.04)$ & $0.02(0.04)$ & $0.01(0.05)$ \\
\hline $\mathrm{R}^{2}$ & 0.81 & 0.84 & 0.85 & 0.80 & 0.88 & 0.87 \\
\hline
\end{tabular}

${ }^{\mathrm{a} P}<0.01$

Table 3

Determinant factors on altruistic willingness to pay for improvement of hypothetical health status.

\begin{tabular}{|c|c|c|c|c|c|c|}
\hline \multirow[t]{2}{*}{ Explanatory Variables } & Model 1 & Model 2 & Model 3 & Model 4 & Model 5 & Model 6 \\
\hline & Log $\mathrm{WTP}_{\mathrm{HS} 1}$ & $\log \mathrm{WTP}_{\mathrm{HS} 2}$ & Log $\mathrm{WTP}_{\mathrm{HS} 3}$ & $\log \mathrm{WTP}_{\mathrm{HS} 4}$ & Log $\mathrm{WTP}_{\mathrm{HS} 5}$ & $\log \mathrm{WTP}_{\mathrm{HS} 6}$ \\
\hline Constant & $-8.39^{\mathrm{a}}$ & $-6.52^{\mathrm{a}}$ & $-5.76^{\mathrm{a}}$ & $-3.44^{\mathrm{a}}$ & $-2.67^{\mathrm{a}}$ & $-1.77^{\mathrm{a}}$ \\
\hline Age & $0.06(0.03)$ & $0.07(0.05)$ & $0.05(0.04)$ & $0.04(0.05)$ & $0.05(0.04)$ & $0.03(0.05)$ \\
\hline Sex & $0.11(0.09)$ & $0.09(0.08)$ & $0.05(0.03)$ & $0.03(0.04)$ & $0.02(0.04)$ & $0.02(0.03)$ \\
\hline Marital status & $0.07(0.05)$ & $0.05(0.03)$ & $0.04(0.05)$ & $0.04(0.03)$ & $0.03(0.02)$ & $0.03(0.04)$ \\
\hline Income & $1.77^{\mathrm{a}}(0.07)$ & $1.84^{\mathrm{a}}(0.09)$ & $1.70^{\mathrm{a}}(0.05)$ & $1.64^{\mathrm{a}}(0.07)$ & $1.86^{\mathrm{a}}(0.08)$ & $1.87^{\mathrm{a}}(0.05)$ \\
\hline Education & $0.07(0.05)$ & $0.05(0.04)$ & $0.04(0.02)$ & $0.14(0.09)$ & $0.18(0.07)$ & $0.27(0.05)$ \\
\hline $\mathrm{R}^{2}$ & 0.83 & 0.87 & 0.89 & 0.82 & 0.89 & 0.89 \\
\hline
\end{tabular}

${ }^{\mathrm{a}} \mathrm{P}<0.01$.

influenced by household monthly income $(\mathrm{P}<0.01)$. According to regression results, in first health status, the increase of $1 \%$ of the household monthly income results in $1.37 \%$ increase in the private WTP. For second to sixth health status, the increase of $1 \%$ of the household monthly income results in $1.26,1.21,1.05,1.03,1.01 \%$ increase in the private WTP (see Table 3 ).

Table 2 shows determinant factors on altruistic WTP in different status of health. The results showed that the mean of willingness to pay was influenced by household monthly income $(\mathrm{P}<0.01)$.

\section{Discussion}

This study aimed to compare altruistic and private willingness to pay for health status with different severity levels. Evidence of altruistic willingness to pay was provided by results. In current study, all patients were willing to pay for altruistic WTP. Existence of altruistic willingness to pay have shown in many studies that were the same by present study results. Javan-Noughabi et al. in a study showed that about $88.8 \%$ of the participants were willing to pay for health status. ${ }^{16}$ Jacobsson et al. in Sweden found evidences for altruistic preference by willingness to pay technique in $2005 .{ }^{17}$ Kalantari et al. concluded that $75.3 \%$ of respondents were willing to pay altruistic activities in Iran. ${ }^{18}$ Culyer et al., demonstrated that people are influenced by others health status directly or indirectly, so, they feel a sense of responsibility for others' health improvement. $^{19}$

The findings of this study also show that the mean value of private WTP is higher than the mean value of the altruistic WTP in all health status. But in worse health status, the mean value difference became greater that means respondents willing to pay private. Hurley and Mentzakis in a study showed that in emergency health state, private WTP was more significant than altruistic WTP. ${ }^{20}$ Jacobsson et al. also found the mean value of the altruistic WTP was lower than the mean value of the private WTP in all health states. they estimated that external benefits was $15-20 \%$ of own-benefits for severe health conditions. ${ }^{17}$ Andersson (2009) resulted that willingness to pay for a traffic safety device that would protect the general public was about one-third of the willingness to pay for a device that protected only each one. ${ }^{11}$
Smith (2007) similarly found average willingness to contribute for the treatment of another person equal to about one-half of the willingness to pay for one's own treatment. ${ }^{21}$ However, the mentioned studies were similar to present study, there are some essays which have different results.

Liu et al. showed that mothers' WTP for their children's health is approximately twice as large as their WTP for themselves. ${ }^{10}$ Other studies also showed that parents' willingness-to-pay for policies to reduce health risks or provide treatment to their children actually exceeds their willingness-to-pay for such gains to themselves. ${ }^{22,23}$ The difference in the results could be due to differences in research group.

\section{Competing interests}

The authors declare that they have no competing interests.

\section{Authors' contributions}

HS, MS: the conception of the study; design of the study. MS, EP: data acquisition; data interpretation; drafting the manuscript. HS: supervision of the study. All authors read and approved the final manuscript.

\section{References}

1. O'Brien B, Gafni A. When do the" dollars" make sense? Toward a conceptual framework for contingent valuation studies in health care. Med Decis Making. 1996;16:288-299.

2. Koopmanschap MA, Rutten FF, van Ineveld BM, et al. The friction cost method for measuring indirect costs of disease. J Health Econ. 1995;14:171-189.

3. Rice DP, Cooper BS. The economic value of human life. Am J Public Health Nation's Health. 1967;57:1954-1966.

4. Johannesson M. Theory and Methods of Economic Evaluation of Health Care. Springer Science \& Business Media; 1996.

5. Diener A, O'Brien B, Gafni A. Health care contingent valuation studies: a review and classification of the literature. Health Econ. 1998;7:313-326.

6. Olsen JA, Smith RD. Theory versus practice: a review of 'willingness-to-pay'in health and health care. Health Econ. 2001;10:39-52.

7. Yeung RY, Smith MRD. Can we use contingent valuation to assess the demand for childhood immunisation in developing countries? Appl Health Econ Health Policy. 2005;4:165-173. 
8. Phillips K, Homan R, Luft H, et al. Costs and Financing of Public Goods: The Case of Poison Control Centres. Abstract Book, Association for Health Services Research; 1997:136-137.

9. Borghi J. Aggregation rules for cost-benefit analysis: a health economics perspective. Health Econ. 2008;17:863-875.

10. Liu J-T, Hammitt JK, Wang J-D, et al. Mother's willingness to pay for her own and her child's health: a contingent valuation study in Taiwan. Health Econ. 2000;9:319-326.

11. Andersson H, Lindberg G. Benevolence and the value of road safety. Accid Anal Prev. 2009;41:286-293.

12. Klose T. The contingent valuation method in health care. Health Policy. 1999;47:97-123

13. Mitchell RC, Carson RT. Using Surveys to Value Public Goods: The Contingent Valuation Method. Resources for the Future; 1989.

14. Arrow K, Solow R, Portney PR, et al. Report of the NOAA panel on contingent valuation. Fed Regist. 1993;58:4601-4614.

15. Nord E. The trade-off between severity of illness and treatment effect in cost-value analysis of health care. Health Policy. 1993;24:227-238.
16. Javan-Noughabi J, Kavosi Z, Faramarzi A, et al. Identification determinant factors on willingness to pay for health services in Iran. 2017;7 40.

17. Jacobsson F, Carstensen J, Borgquist L. Caring externalities in health economic evaluation: how are they related to severity of illness? Health Policy. 2005;73:172-182.

18. Kalantari S, Adibi M, Rabbani R, et al. An Investigation on Apathy and Altruism. Urbam Society Of Iran; 2007.

19. Culyer AJ. Economics and ethics in health care. J Med Ethics. 2001;27:217-222

20. Hurley JE, Mentzakis E. Existence and Magnitude of Health-Related Externalities: Evidence from a Choice Experiment. Centre for Health Economics and Policy Analysis, McMaster University; 2011

21. Smith RD. Use, option and externality values: are contingent valuation studies in health care mis-specified? Health Econ. 2007;16:861-869.

22. Dickie M, Gerking S. Altruism and environmental risks to health of parents and their children. J Environ Econ Manag. 2007;53:323-341.

23. Dickie M, Messman VL. Parental altruism and the value of avoiding acute illness: are kids worth more than parents? J Environ Econ Manag. 2004;48:1146-1174. 